\title{
Skin appendage-derived stem cells: cell biology and potential for wound repair
}

Jiangfan Xie ${ }^{1}$, Bin Yao ${ }^{1,2}$, Yutong Han ${ }^{3}$, Sha Huang ${ }^{1,4^{*}}$ and Xiaobing $\mathrm{Fu}^{1,4^{*}}$

\begin{abstract}
Stem cells residing in the epidermis and skin appendages are imperative for skin homeostasis and regeneration. These stem cells also participate in the repair of the epidermis after injuries, inducing restoration of tissue integrity and function of damaged tissue. Unlike epidermis-derived stem cells, comprehensive knowledge about skin appendage-derived stem cells remains limited. In this review, we summarize the current knowledge of skin appendage-derived stem cells, including their fundamental characteristics, their preferentially expressed biomarkers, and their potential contribution involved in wound repair. Finally, we will also discuss current strategies, future applications, and limitations of these stem cells, attempting to provide some perspectives on optimizing the available therapy in cutaneous repair and regeneration.
\end{abstract}

Keywords: Skin appendages, Stem cells, Cell biology, Wound healing

\section{Background}

Skin as a barrier for resisting external invasion is distributed to every part of the body, which concludes the epidermis and dermis [1]. Morphologically, the epidermis is the structure in the skin's outermost layer, and it together with its derivative appendages protects the organism from the outside, as well as regulates the body temperature and homeostasis [2]. Like other organs, there are some related stem cells in the skin and its derived appendages, which have the capacity to maintain homeostasis, self-renew tissue, and contribute to wound healing [3]. Skin wound healing is a highly organized and coordinated series of processes that leads to the restoration of tissue integrity and function [3]. A slice of factors can cause an interruption in wound healing including systemic and local effects. Systemic effects include compromised nutritional, immune status, diabetes, and advanced age. Local factors include tissue hypoxia, ischemia, foreign bodies, maceration of tissue, exudates, and infection [4]. Several therapies have emerged for chronic wounds, with different degrees of success $[4,5]$.

\footnotetext{
* Correspondence: stellarahuang@sina.com; fuxiaobing@vip.sina.com

'Key Laboratory of Tissue Repair and Regeneration of PLA, and Beijing Key

Research Laboratory of Skin Injury, Repair and Regeneration, First Hospital

Affiliated to General Hospital of PLA, 51 Fu Cheng Road, Beijing 100048,

People's Republic of China

Full list of author information is available at the end of the article
}

However, the report of autoallergic repair by skin appendage-derived progenitor/stem cells remains limited.

This review aimed primarily to introduce the skin appendage-derived progenitor/stem cells, including their characteristics, functions, therapeutic potentials, and limitations as therapeutic tools for wound healing. In the following sections, we defined skin appendage-derived progenitor/stem cells and summarized some of the biomarkers used for their identification based on reported researches, and discussed their potentials in wound healing and limitations.

\section{Review}

Skin appendage-derived progenitor/stem cells

Skin appendages develop during the embryonic period following a precise spatiotemporal pattern involving complex interactions between the cells from primitive epidermis, and ectodermic origin, as well as the underlying mesenchymal cells from mesodermic origin (Fig. 1). Epithelial stem cells rely heavily on quiescence as a major stem cell characteristic, which is due to "labelretaining cell" methods for detecting quiescent cells in the epidermis from the pioneering work of Bickenbach and Mackenzie [6]. 


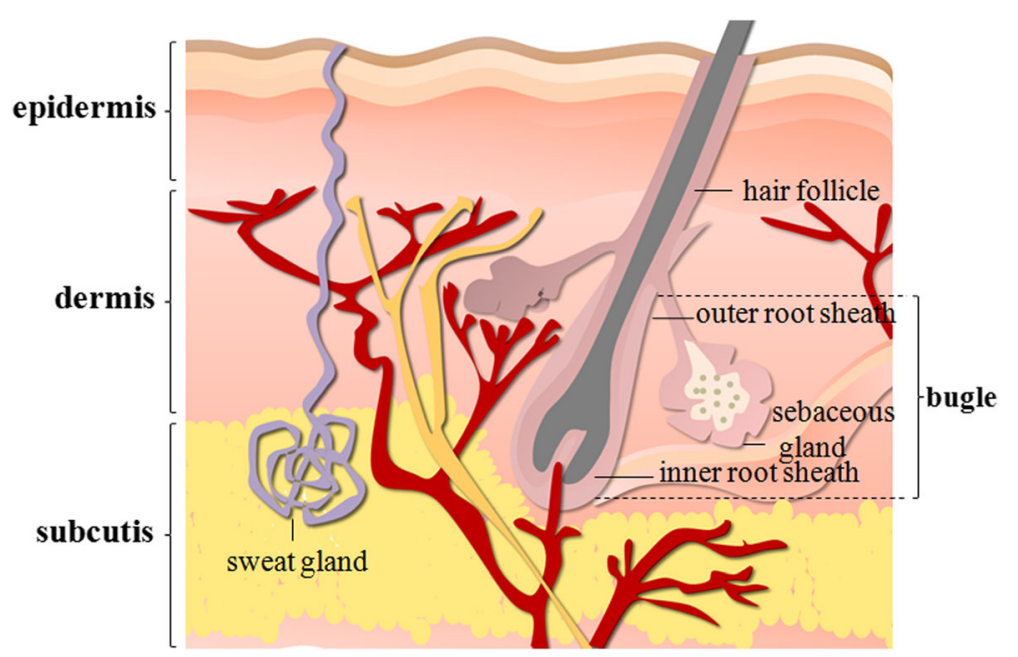

Fig. 1 The schematic diagram of full-thickness skin

\section{Eccrine sweat gland progenitor/stem cells}

Sweat gland as a crucial skin appendage widely exists in the human skin surface, while only distributed on the palm of mice, which plays a pivotal role in the process of temperature regulation and homeostasis $[7,8]$. In human embryos, sweat gland buds begin to emerge on the palms and soles at 12-13 weeks and on the rest of the body at 20 weeks [9]. At 22 gestational weeks of human, myoepithelial cells and luminal cells in the secretory portion can be detected. In mice, sweat gland buds first appear at embryo 16.5 days. It completes maturation at day 14 after birth and fully function at day 21 after birth $[9,10]$. In the process of development, sweat gland germs grow down progressively into the dermis to form a duct, ending in a secretary coil, and play their function basing on the body itself and the changes in the external temperature. The mature sweat glands contain the portion of duct and secretary coil.

Knowledge of the eccrine sweat gland is relatively unified, which is differentiated from epithelial-derived stem cells and its progenitors. Recently, Lu et al. and Van Keymeulen et al. found the existence of two populations of stem cells in the sweat ducts of postnatal mice and four populations in the paw skin of adult mice [11, 12]. Sweat glands begin to develop as a multipotent sweat bud progenitor $\left(\mathrm{K} 4^{+}\right)$during fetal life. After stratification, K18 expression is increased and K14 expression reduced, which generates a transient but proliferative suprabasal layer of progenitors $\left(\mathrm{K} 14^{\text {low }} / \mathrm{K} 18^{+}\right)$[11]. Finally, these basal and suprabasal ductal progenitors continue to differentiate and migrate outwards to form myoepithelial and luminal progenitor cells successively $[11,13]$. In adult paw skin, both luminal progenitors and myoepithelial progenitors at sweat ducts and secretory portion make a significant effect in homeostatic turnover, and each followed distinct basal $\rightarrow$ suprabasal differentiation programs $[11,14]$.

Whether in human or in mice, these cells of sweat glands express a number of characterized markers. Luminal cells of a mature sweat gland express $\mathrm{K} 8$ and K18 [15]. NKA $\alpha$, ATP1a1, and K19 are expressed in the gland portion of a mature sweat gland [16, 17]. K14 and $\mathrm{K} 5$ are found in the myoepithelial cells [10]. K10 is expressed positively in the duct portion of sweat gland

Table 1 The expression patterns of skin appendage markers

\begin{tabular}{|c|c|c|}
\hline Skin appendage & Cells & Markers \\
\hline \multirow[t]{6}{*}{ Sweat gland } & Mature luminal cells & $\mathrm{K} 8, \mathrm{~K} 18$ \\
\hline & Mature gland cells & NKAa, ATP1a1, K19 \\
\hline & Mature myoepithelial cells & $\mathrm{K} 14, \mathrm{~K} 5$ \\
\hline & Mature duct cells & K10 \\
\hline & Stemness & $\begin{array}{l}\text { Nestin, CD9, CD29, } \\
\text { CD44, CD81 }\end{array}$ \\
\hline & Sweat bud progenitor & $\mathrm{K} 14 \rightarrow \mathrm{K} 14 \mathrm{low} / \mathrm{K} 18+$ \\
\hline \multirow[t]{5}{*}{ Hair follicle } & Bugle cells & K15, CD34, SRY box 9 \\
\hline & $\begin{array}{l}\text { Stem cells reside in the } \\
\text { upper isthmus }\end{array}$ & (Plet1)/MTS24, Lrig1 \\
\hline & $\begin{array}{l}\text { Stem cells reside in the } \\
\text { lower isthmus }\end{array}$ & Lgr6 and Gli1 \\
\hline & $\begin{array}{l}\text { Epidermal stem cells in } \\
\text { the HF bulge }\end{array}$ & $\begin{array}{l}\text { GATA3, BMPR1a, ID2, } \\
\text { ID4, Wnt, } \beta \text {-catenin }\end{array}$ \\
\hline & Human hair follicle bulge & $\begin{array}{l}\text { K15, PHLDA1, CD200, } \\
\text { K19 }\end{array}$ \\
\hline Sebaceous gland & Sebaceous gland progenitors & Blimp1, K5, K14 \\
\hline
\end{tabular}

Plet1 placenta transcript 1, Gli1 glioma-associated oncogene homolog 1, GATA3 GATA binding protein 3, BMPR1a bone morphogenetic protein receptor1a, ID2 DNA-binding protein 2, PHLDA1 pleckstrin homology-like domain, family A member 1, CD200 cluster of differentiation 200 
cells [10]. Moreover, we can identify its stemness by Nestin, CD9, CD29, CD44, and CD81 expressed in the sweat glands [17] (Table 1).

\section{Hair follicle progenitor/stem cells}

The morphology of hair follicle begins at the early period of embryo and signals from the epithelium inducing the formation of dermal condensates [2]. The first wave of hair placodes of mouse starts by the mesenchymal-epithelial interactions at embryonic day (E) 14.5 [2]. Once initiated, these placodes undergo proliferation and downgrowth to form first hair germs at E15.5 and hair pegs at E16.5-17.5. Then, the inner root sheath (IRS) provides the channel for the emerging hair (E18.5) [2]. At birth, the mature hairs begin to break the skin surface. After the first postnatal week, the full maturation hair follicle is formed $[2,18]$. In general, there are four waves of follicle morphogenesis during the developmental process of hair follicle, with the large primary guard hairs forming first (E14.5) and followed by the bulk of the hair coat follicles starting to form [19].

Hair follicle stem cells are likely persistent throughout the lifetime of the organism [20]. There are two main subpopulations of stem cells in hair follicles: the one under the bulge gives rise to the hair shaft and IRS and the other residing in the bulge region gives rise to the basal outer root sheath (ORS) keratinocytes [3]. Owing to the characteristic of slow cycling, quiescent nature, clonogenic capability, and the expression of a subset of markers, the bugle region has been known as the most well-defined stem cell niche in the skin [20,21]. The reservoir for follicle stem cells is formed during the process of each new anagen forming $[2,12]$. Moreover, some researchers have found that the offspring of bugle cell can form sebaceous glands and epidermis as well as new hair follicles [22]. It suggests that follicle stem cells only contribute to hair follicle homeostasis, whereas they are not involved in interfollicular epidermis regeneration [23].

In mice, the bugle cells of hair follicle express K15, CD34, and SRY box 9 [24-27]. Stem cells reside in the upper isthmus/junctional zone region can express placenta transcript 1 (Plet1)/MTS24 and Lrig1. Lgr6- and glioma-associated oncogene homologue 1 (Gli1) are expressed in the cells which are located in the lower isthmus $[28,29]$. Furthermore, GATA binding protein 3 (GATA3), bone morphogenetic protein receptor1a (BMPR1a), the inhibitors of DNA-binding protein 2 and 4 (ID2, ID4), and Wnt and $\beta$-catenin also can regulate epidermal stem cells and their fate in the hair follicle (HE) bulge [30]. K15, pleckstrin homology-like domain, family A member 1 (PHLDA1), cluster of differentiation 200 (CD200), and K19-positive cells can be found in the human hair follicle bulge too [31, 32] (Table 1).

\section{Sebaceous gland progenitor/stem cells}

Sebaceous gland as an integral philosebaceous unit resides above the bugle and under the hair shaft orifice at the skin surface and secretes sebum to lubricate the skin and keeps the waterproof property of hair in mammals [2]. In human embryos, sebaceous glands begin to emerge approximately at $13-14$ weeks $[7,33]$. In mice, sebaceous glands develop around the end of embryogenesis and fully function after birth [7,33]. At birth, the sebaceous gland precursor cells form the upper segment of the root. Moreover, Horsley et al. have found that a small population of cells near or at the base of sebaceous glands maintained stemness [34]. Furthermore, sebaceous gland progenitors of normal mice express Blimp-1 [34]. And the Blimp1-positive sebaceous gland cells also express K5/K14 [3] (Table 1).

\section{Other skin appendage-derived progenitor/stem cells}

Except for eccrine sweat glands, hair follicle, and sebaceous glands, there are other appendages in the epidermis including melanocytes. Melanocyte stem cells mainly reside in the hair follicle bulge region and hair germ, which express dopachrome tautomerase, Sox10, and paired box 3 [35]. These stem cells form mature melanocytes in the hair follicle bulb. Several studies have demonstrated that cell-cell interaction in epidermal stem cells via Wnt signaling, TGF- $\beta$, notch signaling, nuclear factor I/B (NFIB), and Col17a1 can regulate melanocyte stem cells [36, 37]. Notably, melanocyte stem cells could migrate upwards to the interfollicular epidermis (IFE) and differentiate into functional epidermal melanocytes contributing to the wound healing $[38,39]$.

\section{Potential of skin appendage-derived progenitor/stem cells for wound repair}

Skin as the first barrier of our body resists the encroachment. Thus the rapid repair is crucial to maintain its function. Previous studies using lineage tracing and mouse models indicated that stem cells of both the epidermis and its appendages contribute to skin wound healing.

\section{Eccrine sweat gland progenitor/stem cells in wound healing}

To search decisional assessment of the source of stem cells in wound healing process, $\mathrm{Lu}$ et al. marked four stem cell populations and established new models [11]. They revealed that eccrine sweat ductal cells migrated and repaired an epidermal scratch wound in 3 days and restored the intraepidermal sweat ducts in 14 days. Only sweat ductal basal progenitors responded and proliferated to repair the duct orifice extending throughout the skin surface, indicating that sweat duct is the growth center after epidermis injury. In contrast, luminal and myoepithelial cells from the secretory section of sweat 
glands functioned as unipotent progenitors during glandular repair. These findings provided evidence that sweat gland stem cells might possess significant potential for clinical applications including extensive burns and massive skin loss [40]. Although ductal stem cells seemed accused on repairing the sweat duct orifice, the epidermal stem cells adjacent to the wound showed more athletic in epidermal repair, which indicated that both ductal and epidermal progenitors participate in epidermal wound repair [41]. Our research group has explored a series of strategies to facilitate sweat gland regeneration on wound healing. MSCs exist in bone marrow stroma, which are relatively slight damged during isolation and easily activated in large area burn and trauma. Moreover, others' pre-researches and ours have proved that MSCs are directly involved in the whole process of repairing and regeneration of skin damage, including sweat gland repair [42, 43]. Based on these backgrounds, the studies of our laboratory have confirmed that MSCs cultured in vitro could differentiate into cells with the phenotype of sweat gland cells. If these MSCs were transplanted into the wound, they could be transformed into vascular endothelial cells, epidermal cells, sebaceous duct cells, and sweat gland cells in granulation tissue [43, 44]. Meanwhile, Huang et al. have showed that the epidermal stem cells could be induced into sweat glands like cells with sweat gland function under 3D-printed microenvironment [45].

\section{Hair follicle and sebaceous gland progenitor/stem cells in wound healing}

Both clinical and experimental evidence suggest that hair follicle and sebaceous gland progenitor cells contribute to the re-epithelialization of wounds [23]. Some researchers have shown that cells from hair follicles and IFE would migrate to the wound portion in fullthickness [23]. Fate-mapping experiments demonstrated that hair follicle stem cells only exist in wounds [23]. In response to skin injury, Gli1+, Lrig1+, Lrg5+, and MT24 + cells become activated and contribute towards IFE repair, suggesting the plasticity of epidermal stem cells $[46,47]$. Jimenez et al. evaluated the feasibility and potential healing capacity of autologous scalp follicular grafts transplanted into the wound by detecting the epithelialization, neovascularization, and dermal reorganization of chronic leg ulcers in ten patients after 18 weeks, demonstrating hair follicle grafting as a promising therapeutic strategy for non-healing chronic wounds [48]. Moreover, other group reported that hair follicle progenitors were largely replaced by epidermal progeny in wound healing [49]. These findings suggest that both IFE and hair follicle stem cells contribute to wound healing $[50,51]$.
Some researchers confirmed that the stem cells of the root sheath and bugle can repair not only the hair follicle but also the sebaceous gland on the process of wound healing $[2,23]$. Sweat gland stem cells can renew themselves and repair epidermis on wound healing [9]. Although previous studies revealed that stem cells of these skin appendages contribute to skin wound repair, the interaction among these appendage-derived progenitor/stem cells on wound healing is still unclear [23, 47]. Because there are more sweat glands than hair follicles in the majority area of human skin, it has been hypothesized that sweat gland would assist other skin appendages on wound healing, and the concrete mechanism and evidence needed to further explore.

\section{Limits of skin appendage-derived progenitor/stem cell application}

Skin appendages or appendage-derived stem cells have thrilled so many biomedical researchers over the last 10 years. PubMed, in 2015, collected over 867 references for "skin appendage" and more than 7725 for "skin appendage-derived stem cells." Part of them are comprehensive recent reviews on skin appendages and skin appendage-derived stem cells. However, studies treating wound healing with these stem cells are rare. We summarized limitations and difficulties from different points of view about skin appendage-derived stem cells on wound healing.

The cell source is certainly limited. Lu et al. found four types stem cells of the eccrine sweat gland at 2012 [11], while the specific methods of isolating stem cells of the eccrine sweat glands could only get limited numbers. Other investigators also explored knowledge of hair follicle- and sebaceous gland-derived stem cells, but the isolating methods are absent. Because of the special period and portion and limited quantity of appendagederived stem cells, they are difficult to isolate and purify. Moreover, although there are many researches of skin appendage-derived stem cells on wound healing recently, the mechanisms at molecular and cellar level are not distinct.

Mice were the most commonly used animal mode for researches of skin appendage-derived stem cells, but it is difficult to establish the identical wound. We usually established chronic non-healing wounds mice model through burns or diabetes mellitus wounds, while the changes were not only involved in wound region. For example, a burn patient would not only develop a series of metabolic changes in wound site but also have significant change of homeostasis of the whole body, such as water and salt balance. In chronic non-healing wounds caused by diabetes in patients usually with elder age, they might have diseases including hypertension, hyperlipidemia, and renal involvement generally. The complex 
symptom is difficult to completely reproduce in animal models. Stem cell therapy is usually directly injected to the specific site or intravenous injection, but the exact number of cells that arrived at the wound site and the interaction time could not be determined. Hence, a suitable approach to study the role of stem cells in the wound site is in urgent need. Not to mention, there are some problems that blocked the transformation of basic experiments to clinical trials.

\section{Conclusions}

In this review, we have discussed the characteristics and functions of eccrine sweat gland-, hair follicle-, and sebaceous gland-derived progenitor/stem cells as well as summarized the relationship, potential, and limits of these stem cells on wound healing. We mainly elucidated the roles of skin appendage-derived progenitor/stem cells in wound healing, associated with their development and molecular mechanisms. Chronic non-healing wounds are common and need to be paid attention. Skin appendagederived progenitor/stem cells could reduce the immune response and promote repair. To figure out the comprehensive cellular interactions and stem cell behavior would facilitate wound healing. With the knowledge of skin appendage-derived progenitor/stem cells recently showed that choosing the right stem cell type for fully functional skin regeneration in vivo is extremely important. Furthermore, identifying and isolating pure skin appendagederived progenitor/stem cell populations, exploring the underlying mechanisms, and optimizing protocols for cell delivering to appropriate portion need to be further explored. Moreover, we need more clinical trials to further explore the long-term effects with these cells and ultimately provide safer and more effective therapies for future clinical applications.

\section{Acknowledgements}

This paper was supported in part by the National Nature Science Foundation of China $(81121004,81230041,81372066,81571909)$ and the National Basic Science and Development Program (973 Program, 2012CB518105).

\section{Funding}

This paper was supported in part by the National Nature Science Foundation of China (81121004, 81230041, 81372066, 81571909) and the National Basic Science and Development Program (973 Program, 2012CB518105).

\section{Availability of data and materials}

Not applicable.

\section{Authors' contributions}

JX was responsible for the design and wrote the manuscript. BY and $\mathrm{YH}$ contributed to parts of the writing. SH and XF were responsible for the design and revised the manuscript. All authors read and approved the final manuscript.

\section{Competing interests}

The authors declare that they have no competing interests.

Consent for publication

Not applicable.
Ethics approval and consent to participate

Not applicable.

\section{Author details}

${ }^{1}$ Key Laboratory of Tissue Repair and Regeneration of PLA, and Beijing Key Research Laboratory of Skin Injury, Repair and Regeneration, First Hospital Affiliated to General Hospital of PLA, 51 Fu Cheng Road, Beijing 100048, People's Republic of China. ${ }^{2}$ School of Medicine, Nankai University, Tianjin 300052, People's Republic of China. ${ }^{3}$ Graduate School of the Second Teaching Hospital of Zhengzhou University, Zhengzhou 450000, People's Republic of China. "Wound Healing and Cell Biology Laboratory, Institute of Basic Medical Sciences, General Hospital of PLA, Beijing 100853, People's Republic of China.

Received: 7 July 2016 Accepted: 4 October 2016

Published online: 26 October 2016

\section{References}

1. Lee SH, Jeong SK, Ahn SK. An update of the defensive barrier function of skin. Yonsei Med J. 2006:47:293-306.

2. Fuchs E. Skin stem cells: rising to the surface. J Cell Biol. 2008;180:273-84.

3. Ojeh N, Pastar I, Tomic-Canic M, Stojadinovic O. Stem cells in skin regeneration, wound healing, and their clinical applications. Int J Mol Sci. 2015;16:25476-501.

4. Eming SA, Martin P, Tomic-Canic M. Wound repair and regeneration: mechanisms, signaling, and translation. Sci Transl Med. 2014;6:265s-6.

5. Fonder MA, Lazarus GS, Cowan DA, Aronson-Cook B, Kohli AR, Mamelak AJ. Treating the chronic wound: a practical approach to the care of nonhealing wounds and wound care dressings. J Am Acad Dermatol. 2008;58:185-206.

6. Bickenbach JR, Mackenzie IC. Identification and localization of labelretaining cells in hamster epithelia. J Invest Dermatol. 1984;82:618-22.

7. Liu S, Zhang H, Duan E. Epidermal development in mammals: key regulators, signals from beneath, and stem cells. Int J Mol Sci. 2013;14: 10869-95.

8. Rinn JL, Wang JK, Allen N, Brugmann SA, Mikels AJ, Liu H, et al. A dermal HOX transcriptional program regulates site-specific epidermal fate. Genes Dev. 2008;22:303-7.

9. Lu C, Fuchs E. Sweat gland progenitors in development, homeostasis, and wound repair. Cold Spring Harb Perspect Med. 2014;4.

10. Xie J, Yao B, Han Y, Shang T, Gao D, Yang S, et al. Cytokeratin expression at different stages in sweat gland development of C57BL/6J mice. Int J Low Extrem Wounds. 2015;14:365-71.

11. Lu CP, Polak L, Rocha AS, Pasolli HA, Chen SC, Sharma N, et al. Identification of stem cell populations in sweat glands and ducts reveals roles in homeostasis and wound repair. Cell. 2012;150:136-50.

12. Van Keymeulen A, Rocha AS, Ousset M, Beck B, Bouvencourt G, Rock J, et al. Distinct stem cells contribute to mammary gland development and maintenance. Nature. 2011:479:189-93.

13. Shackleton M, Vaillant F, Simpson KJ, Stingl J, Smyth GK, Asselin-Labat ML, et al. Generation of a functional mammary gland from a single stem cell. Nature. 2006:439:84-8.

14. Lobitz WJ, Holyoke JB, Brophy D. Response of the human eccrine sweat duct to dermal injury. J Invest Dermatol. 1956;26:247-59. 259-262.

15. Biedermann T, Pontiggia L, Bottcher-Haberzeth S, Tharakan S, Braziulis E, Schiestl C, et al. Human eccrine sweat gland cells can reconstitute a stratified epidermis. J Invest Dermatol. 2010;130:1996-2009.

16. Fu XB, Sun TZ, Li XK, Sheng ZY. Morphological and distribution characteristics of sweat glands in hypertrophic scar and their possible effects on sweat gland regeneration. Chin Med J (Engl). 2005;118:186-91.

17. Schon M, Benwood J, O'Connell-Willstaedt T, Rheinwald JG. Human sweat gland myoepithelial cells express a unique set of cytokeratins and reveal the potential for alternative epithelial and mesenchymal differentiation states in culture. J Cell Sci. 1999;112(Pt 12):1925-36.

18. Schmidt-Ullrich R, Paus R. Molecular principles of hair follicle induction and morphogenesis. BioEssays. 2005;27:247-61.

19. Mokos ZB, Mosler EL. Advances in a rapidly emerging field of hair follicle stem cell research. Coll Antropol. 2014;38:373-8.

20. Blanpain C, Fuchs E. Epidermal stem cells of the skin. Annu Rev Cell Dev Biol. 2006;22:339-73. 
21. Oshima H, Rochat A, Kedzia C, Kobayashi K, Barrandon Y. Morphogenesis and renewal of hair follicles from adult multipotent stem cells. Cell. 2001; 104:233-45.

22. Cotsarelis $\mathrm{G}$, Sun $\Pi$, Lavker RM. Label-retaining cells reside in the bulge area of pilosebaceous unit: implications for follicular stem cells, hair cycle, and skin carcinogenesis. Cell. 1990;61:1329-37.

23. Ito M, Liu Y, Yang Z, Nguyen J, Liang F, Morris RJ, et al. Stem cells in the hair follicle bulge contribute to wound repair but not to homeostasis of the epidermis. Nat Med. 2005;11:1351-4.

24. Liu Y, Lyle S, Yang Z, Cotsarelis G. Keratin 15 promoter targets putative epithelial stem cells in the hair follicle bulge. J Invest Dermatol. 2003;121: 963-8.

25. Trempus CS, Morris RJ, Bortner CD, Cotsarelis G, Faircloth RS, Reece JM, et al. Enrichment for living murine keratinocytes from the hair follicle bulge with the cell surface marker CD34. J Invest Dermatol. 2003;120:501-11.

26. Jaks V, Barker N, Kasper M, van Es JH, Snippert HJ, Clevers H, et al. Lgr5 marks cycling, yet long-lived, hair follicle stem cells. Nat Genet. 2008;40: 1291-9.

27. Nowak JA, Polak L, Pasolli HA, Fuchs E. Hair follicle stem cells are specified and function in early skin morphogenesis. Cell Stem Cell. 2008;3:33-43.

28. Blanpain C. Stem cells: skin regeneration and repair. Nature. 2010;464:686-7.

29. Brownell I, Guevara E, Bai CB, Loomis CA, Joyner AL. Nerve-derived sonic hedgehog defines a niche for hair follicle stem cells capable of becoming epidermal stem cells. Cell Stem Cell. 2011;8:552-65.

30. Lowry WE, Blanpain C, Nowak JA, Guasch G, Lewis L, Fuchs E. Defining the impact of beta-catenin/Tcf transactivation on epithelial stem cells. Genes Dev. 2005;19:1596-611.

31. Michel M, Torok N, Godbout MJ, Lussier M, Gaudreau P, Royal A, et al. Keratin 19 as a biochemical marker of skin stem cells in vivo and in vitro: keratin 19 expressing cells are differentially localized in function of anatomic sites, and their number varies with donor age and culture stage. J Cell Sci. 1996:109(Pt 5):1017-28.

32. Sellheyer K, Krahl D. PHLDA1 (TDAG51) is a follicular stem cell marker and differentiates between morphoeic basal cell carcinoma and desmoplastic trichoepithelioma. Br J Dermatol. 2011;164:141-7.

33. Niemann C, Horsley V. Development and homeostasis of the sebaceous gland. Semin Cell Dev Biol. 2012;23:928-36.

34. Horsley V, O'Carroll D, Tooze R, Ohinata Y, Saitou M, Obukhanych T, et al. Blimp1 defines a progenitor population that governs cellular input to the sebaceous gland. Cell. 2006;126:597-609.

35. Osawa M, Egawa G, Mak SS, Moriyama M, Freter R, Yonetani S, et al. Molecular characterization of melanocyte stem cells in their niche. Development. 2005;132:5589-99.

36. Chang CY, Pasolli HA, Giannopoulou EG, Guasch G, Gronostajski RM, Elemento $\mathrm{O}$, et al. NFIB is a governor of epithelial-melanocyte stem cell behaviour in a shared niche. Nature. 2013;495:98-102.

37. Tanimura S, Tadokoro Y, Inomata K, Binh NT, Nishie W, Yamazaki S, et al. Hair follicle stem cells provide a functional niche for melanocyte stem cells. Cell Stem Cell. 2011;8:177-87.

38. Lin JY, Fisher DE. Melanocyte biology and skin pigmentation. Nature. 2007; 445:843-50.

39. Chou WC, Takeo M, Rabbani P, Hu H, Lee W, Chung YR, et al. Direct migration of follicular melanocyte stem cells to the epidermis after wounding or UVB irradiation is dependent on Mc1r signaling. Nat Med. 2013;19:924-9.

40. Rittie L, Sachs DL, Orringer JS, Voorhees JJ, Fisher GJ. Eccrine sweat glands are major contributors to reepithelialization of human wounds. Am J Pathol. 2013;182:163-71.

41. Miller SJ, Burke EM, Rader MD, Coulombe PA, Lavker RM. Re-epithelialization of porcine skin by the sweat apparatus. J Invest Dermatol. 1998;110:13-9.

42. Fu X, Qu Z, Sheng Z. Potentiality of mesenchymal stem cells in regeneration of sweat glands. J Surg Res. 2006;136:204-8.

43. Fu X, Fang L, Li X, Cheng B, Sheng Z. Enhanced wound-healing quality with bone marrow mesenchymal stem cells autografting after skin injury. Wound Repair Regen. 2006;14:325-35.

44. Li H, Fu X, Ouyang Y, Cai C, Wang J, Sun T. Adult bone-marrow-derived mesenchymal stem cells contribute to wound healing of skin appendages. Cell Tissue Res. 2006:326:725-36.

45. Huang S, Yao B, Xie J, Fu X. 3D bioprinted extracellular matrix mimics facilitate directed differentiation of epithelial progenitors for sweat gland regeneration. Acta Biomater. 2016;32:170-7.
46. Jensen KB, Collins CA, Nascimento E, Tan DW, Frye M, Itami S, Watt FM. Lrig1 expression defines a distinct multipotent stem cell population in mammalian epidermis. Cell Stem Cell. 2009;4:427-39.

47. Snippert HJ, Haegebarth A, Kasper M, Jaks V, van Es JH, Barker N, et al. Lgr6 marks stem cells in the hair follicle that generate all cell lineages of the skin. Science. 2010;327:1385-9.

48. Jimenez F, Garde C, Poblet E, Jimeno B, Ortiz J, Martinez ML, et al. A pilot clinical study of hair grafting in chronic leg ulcers. Wound Repair Regen. 2012:20:806-14

49. Navsaria HA, Ojeh NO, Moiemen N, Griffiths MA, Frame JD. Reepithelialization of a full-thickness burn from stem cells of hair follicles micrografted into a tissue-engineered dermal template (Integra). Plast Reconstr Surg. 2004;113:978-81.

50. Rompolas P, Mesa KR, Greco V. Spatial organization within a niche as a determinant of stem-cell fate. Nature. 2013;502:513-8.

51. Compton CC, Nadire KB, Regauer S, Simon M, Warland G, O'Connor NE, et al. Cultured human sole-derived keratinocyte grafts re-express sitespecific differentiation after transplantation. Differentiation. 1998;64:45-53.

\section{Submit your next manuscript to BioMed Central and we will help you at every step:}

- We accept pre-submission inquiries

- Our selector tool helps you to find the most relevant journal

- We provide round the clock customer support

- Convenient online submission

- Thorough peer review

- Inclusion in PubMed and all major indexing services

- Maximum visibility for your research

Submit your manuscript at www.biomedcentral.com/submit
) Biomed Central 